\title{
Serum complexes of insulin-like growth factor-1 modulate skeletal integrity and carbohydrate metabolism
}

\author{
Shoshana Yakar, ${ }^{*},{ }^{1}$ Clifford J. Rosen, ${ }^{\dagger}$ Mary L. Bouxsein, ${ }^{\ddagger}$ Hui Sun, ${ }^{*}$ Wilson Mejia, ${ }^{*}$ \\ Yuki Kawashima,* Yingjie Wu,* Kelly Emerton,* Valerie Williams,* Karl Jepsen,* \\ Mitchell B. Schaffler,* Robert J. Majeska,* Oksana Gavrilova, ${ }^{\S}$ Mariana Gutierrez," \\ David Hwang, ${ }^{\text {I }}$ Patricia Pennisi, ${ }^{\$}$ Jan Frystyk, ${ }^{*}$ Yves Boisclair, ${ }^{* *}$ John Pintar, ${ }^{\dagger \dagger}$ \\ Héctor Jasper," Horacio Domene, ${ }^{\|}$Pinchas Cohen, ${ }^{\mathrm{I}}$ David Clemmons, ${ }^{+\ddagger}$ and \\ Derek LeRoith* \\ *Endocrine and Orthopedics Divisions, Mount Sinai School of Medicine, New York, New York, USA; \\ ${ }^{\dagger}$ Maine Medical Center Research Institute, Scarborough, Maine, USA; ${ }^{\ddagger}$ Orthopedic Biomechanics \\ Laboratory, Beth Israel Deaconess Medical Center, Harvard Medical School, Boston, Massachusetts, \\ USA; ${ }^{\S}$ Metabolic Core, National Institute of Diabetes and Digestive and Kidney Diseases, National \\ Institutes of Health, Bethesda, Maryland USA; ${ }_{\text {Endocrinology Research Center, Division of }}$ \\ Endocrinology, R. Gutierrez Children’s Hospital, Buenos Aires, Argentina; `Division of Pediatric \\ Endocrinology, Mattel Hospital for Children, David Geffen School of Medicine, Los Angeles \\ California, USA; "Medical Research Laboratories, Clinical Institute and Medical Department M \\ (Diabetes and Endocrinology), Aarhus University Hospital, Norrebrogade, Aarhus, Denmark; \\ **The Department of Animal Science, Cornell University, Ithaca, New York, USA; ${ }^{\dagger \dagger}$ Department of \\ Neuroscience and Cell Biology, University of Medicine and Dentistry of New Jersey, Piscataway, New \\ Jersey, USA; and ${ }^{\ddagger+}$ Division of Endocrinology, University of North Carolina at Chapel Hill, Chapel \\ Hill, North Carolina, USA
}

ABSTRACT Serum insulin-like growth factor (IGF) -1 is secreted mainly by the liver and circulates bound to IGF-binding proteins (IGFBPs), either as binary complexes or ternary complexes with IGFBP-3 or IGFBP-5 and an acid-labile subunit (ALS). The purpose of this study was to genetically dissect the role of IGF-1 circulatory complexes in somatic growth, skeletal integrity, and metabolism. Phenotypic comparisons of controls and four mouse lines with genetic IGF-1 deficitsliver-specific IGF-1 deficiency (LID), ALS knockout (ALSKO), IGFBP-3 (BP3) knockout, and a triply deficient LID/ALSKO/BP3 line-produced several novel findings. 1) All deficient strains had decreased serum IGF-1 levels, but this neither predicted growth potential or skeletal integrity nor defined growth hormone secretion or metabolic abnormalities. 2) IGF-1 deficiency affected development of both cortical and trabecular bone differently, effects apparently dependent on the presence of different circulating IGF-1 complexes. 3) IGFBP-3 deficiency resulted in increased linear growth. In summary, each IGF-1 complex constituent appears to play a distinct role in determining skeletal phenotype, with different effects on cortical and trabecular bone compartments.-Yakar, S., Rosen, C. J., Bouxsein, M. L., Sun, H., Mejia, W., Kawashima, Y., Wu, Y., Emerton, K., Williams, V., Jepsen, K., Schaffler, M. B., Majeska, R. J., Gavrilova, O., Gutierrez, M., Hwang, D., Pennisi, P., Frystyk, J., Boisclair, Y., Pintar, J., Jasper, H., Domene, H., Cohen, P., Clem- mons, D., LeRoith, D. Serum complexes of insulin-like growth factor-1 modulate skeletal integrity and carbohydrate metabolism. FASEB J. 23, 000-000 (2009)

Key Words: cortical bone $\cdot$ trabecular bone $\cdot$ osteoblast $\cdot$ osteoclast $\cdot$ ternary complex $\cdot$ binary complex

THE GROWTH HORMONE (GH) / INSULIN-LIKE growth factor (IGF) -1 axis is a major regulator of postnatal growth (1); however, understanding its roles in development and physiology is complicated by two interdependent factors. First, IGF-1 exerts both endocrine and autocrine/paracrine effects. IGF-1 is produced both by the liver, primarily under pituitary GH control and by extrahepatic tissues, under regulation by tissue-specific factors (CCAAT/enhancer-binding protein $\alpha$, latencyassociated protein, hepatic nuclear factor- $1 \alpha$, hepatic nuclear factor-3 $\beta$, and CCAAT/enhancer-binding protein $\delta$ ) as well as GH (2-4). Second, circulating IGF-1 forms complexes with a family of high-affinity IGFbinding proteins (IGFBPs) that protect it from proteolytic degradation (5) and also regulate its ability to activate receptors on its target cells. Circulating IGF-1

\footnotetext{
${ }^{1}$ Correspondence: Endocrinology/Diabetes and Bone Disease, The Mt. Sinai School of Medicine, One Gustave L Levy Place, Box 1055, New York, NY 10029-6574, USA. E-mail: shoshana.yakar@mssm.edu doi: 10.1096/fj.08-118976
} 
from both liver and extrahepatic tissues mostly exists as a high molecular weight $(\sim 150 \mathrm{kDa})$ complex with IGFBP-3 and an acid-labile subunit (ALS), both of which are predominantly produced by the liver under GH regulation (6-9). It is believed that once the ternary complex dissociates, the binary complexes of IGFBP-IGF cross the endothelium and interact with target tissues. ALS remains in the vascular compartment, suggesting that its main role is to increase the half-life of circulating IGF-1/IGFBP complexes (10).

At target tissues, IGFBPs may either reduce or enhance the effectiveness of IGF-1. IGFBPs can limit access of IGF-1 to cell surface IGF-1 receptors (IGF1Rs), as IGFBPs have higher affinity for IGF-1 than this receptor does $(11,12)$. In addition, IGFBPs can act as reservoirs that slowly release ligand, allowing prolonged IGF action in local microenvironments $(13,14)$. Furthermore, some IGFBPs can have IGF-1-independent effects on cells $(15,16)$.

To distinguish endocrine from autocrine/paracrine effects of IGF-1 and to define the influence of various IGFBPs on IGF function, we and others have used animal models in which IGF-1 or its binding proteins were genetically ablated. Liver-specific deletion of the igf-1 gene (LID mouse) abolished IGF-1 mRNA expression in liver and dramatically reduced (80\%) circulating IGF-1 levels with no apparent changes in extrahepatic IGF-1 mRNA expression (17). Lacking enough IGF-1 to provide feedback inhibition, serum GH levels were elevated 4-fold in LID mice (17). LID mice also had a $50 \%$ decrease in IGFBP-3. Surprisingly, overall growth of LID mice, as determined by body weight, was not different from that of their control littermates. However, LID mice showed both a modest shortening in bone length $(6 \%)$ and a marked reduction in femoral volumetric bone mineral density (BMD) (18). Carbohydrate metabolism was also altered, as LID mice exhibited a 4-fold increase in serum insulin, plus insulin resistance in liver, muscle, and white adipose tissue (19). These alterations were attributed to increased GH levels, which antagonize insulin action in peripheral tissues (20). These findings confirmed that hepatic IGF-1 is the major source of circulating IGF-1 in mice and provided direct evidence for the importance of extrahepatic IGF-1 in growth and development.

Genetic inactivation of the mouse ALS gene [ALS knockout (ALSKO)] produced a "serum phenotype" resembling LID mice in IGF-1 and IGFBP-3 levels (21), but a different phenotype in terms of growth and metabolism. Despite a $60 \%$ reduction in circulating IGF-1 and a 90\% reduction in IGFBP-3, ALSKO mice showed no increase in serum GH (18). Moreover, despite similar $(7 \%)$ reductions in bone length in LID and ALSKO mice, ALSKO mice exhibited a greater reduction in cortical bone (18). Finally, insulin levels and insulin sensitivity in ALSKO mice were similar to those of controls (22).

Inactivation of the IGFBP-3 gene, the main IGF-1 binding protein in serum, resulted in a $40 \%$ decrease in serum IGF-1 levels with no detectable increases in serum GH and no differences in body weight compared with controls (23). On the other hand, overexpression of IGFBP-3 produced paradoxical phenotypes. In some mouse models, IGFBP-3 overexpression resulted in selective organomegaly, attributed to high levels of the binary IGF-1/IGFBP-3 complex in the circulation (2426); however, in other models in which systemic expression was achieved, both in utero and postnatal growth retardation occurred (27).

Although useful in defining the role of IGF-1 in linear skeletal growth, animal models using genetically modified levels of IGF-1 and/or binding proteins still have substantial limitations, including the ability to achieve only partial reductions in serum IGF-1 levels. Even with the most dramatic reduction in serum IGF-1 levels ( $80 \%$ in LID mice), sufficient circulating IGF-1 remains to preclude unambiguous assignment of effects to locally produced $v$ s. circulating IGF-1. In the present study, we combined LID, ALSKO, and BP3KO mouse models to 1 ) achieve more complete reductions in circulating IGF-1 and 2) compare directly IGF-1 actions when combined with different sets of binding proteins. Our results indicate that the mode of IGF-1 presentation to target tissues, depending on the binding proteins available for complex formation, plays a greater role in determining the biological actions of IGF-1 than its absolute levels in serum. Furthermore, we show that each IGF-1 complex constituent plays a distinct role in determining skeletal phenotype, with different effects on cortical and trabecular bone.

\section{MATERIALS AND METHODS}

\section{Animals}

LID, ALSKO, and BP3KO mouse strains were crossed to produce new double mutant strains (in all combinations) and a triple mutant [LID/ALSKO/BP3KO (LAB)]. All mouse strains in this study were backcrossed at least 6 generations to a C57BL6/J background. Mice were housed 4/cage in a clean mouse facility, fed standard mouse chow (Purina Laboratory Chow 5001; Purina Mills, St. Louis, MO, USA) and water ad libitum, and kept on a 12-h light/dark cycle. Animal care and maintenance were provided through the National Institutes of Health and Mount Sinai School of Medicine Association for Assessment and Accreditation of Laboratory Animal Careaccredited animal facility. All procedures were approved by the Animal Care and Use Committees of the National Institute of Diabetes and Digestive and Kidney Diseases and the Mount Sinai School of Medicine.

\section{Determination of serum hormone levels}

Mice were bled through the mandibular vein, and serum samples were collected at 4, 8, and 16 wk of age. Serum IGF-1, GH, leptin, and insulin levels were determined using commercial radioimmunoassays $(18,20,28)$. A ligand blot assay was performed as described previously (19). Serum levels of mouse IGFBP-2, IGFBP-3, and ALS were determined using ELISA assays developed at UCLA, with recombinant mouse proteins from R\&D Systems (Minneapolis MN, USA) and monoclonal antibodies as described previ- 
ously (29). IGFBP-5 levels were determined by Western blot analysis using IGFBP-5-specific antibody developed at the Division of Endocrinology, University of North Carolina (Chapel Hill, NC, USA) (30).

\section{Determination of ${ }^{125}$ I-IGF-1 half-life in serum of IGF-1-deficient mice}

Mice were injected with $0.3 \mu \mathrm{Ci}$ of ${ }^{125}$ I-IGF-1 through the tail vein and bled from the tail vein $(20-30 \mu \mathrm{l})$ at the indicated time points, according to the Institutional Animal Care and Use Committee protocol for multiple blood sampling (31). Initial (time 0) samples were taken 2-5 s after injection. Each mouse was processed individually, and therefore the time between injection and bleeding was similar among mice. In preliminary experiments, i.v. injections of toluidine blue verified rapid distribution to the peripheral tissues). Serum was separated and $10-\mu \mathrm{l}$ aliquots were incubated with $10 \mu \mathrm{l}$ of $10 \mathrm{mg} / \mathrm{ml} \mathrm{BSA}$, precipitated with $10 \%$ trichloroacetic acid and counted. Values are plotted as a percentage of time 0 counts.

\section{Determination of serum IGF-1 ternary complex formation}

As adopted from Baxter et al. (32), 100- $\mu$ l serum samples were incubated overnight at $22^{\circ} \mathrm{C}$ with ${ }^{125}$ I-IGF-1 (final concentration $10 \mathrm{ng} / \mathrm{ml}$ ) and then cross-linked with disuccinimidyl suberate (33). Complexes were separated using HiPrep 16/60 Sephacryl S-200 HR columns, and 1-ml fractions were collected and counted.

\section{Determination of body composition}

Body adiposity levels were measured using a Bruker mq10 minispec nuclear magnetic resonance analyzer (Bruker Optics, Woodlands, TX, USA) in nonanesthetized mice.

\section{Determination of bone microarchitecture}

Trabecular and cortical bone microarchitecture in the distal femur and femoral diaphysis, respectively, were analyzed by microcomputed tomography ( $\mu$ CT 40, Scanco Medical AG, Basserdorf, Switzerland), as described previously $(28,34)$. For trabecular bone regions, the bone volume fraction $(\mathrm{BV} / \mathrm{TV}$, $\%)$, trabecular thickness $(\mu \mathrm{m})$, trabecular number $\left(\mathrm{mm}^{-1}\right)$, and trabecular separation $(\mu \mathrm{m})$ were assessed. For cortical bone at the femoral midshaft, we measured average total cross-sectional area inside the periosteal envelope $\left(\mathrm{mm}^{2}\right)$, the cortical bone and medullary area within this same envelope $\left(\mathrm{mm}^{2}\right)$, the bone area fraction $(\%)$, the polar moment of inertia $\left(\mathrm{m}^{4}\right)$, and the average cortical thickness $(\mu \mathrm{m})$.

\section{Gene expression studies}

Total RNA from livers and bone marrow cultures was extracted (TRIzol; Invitrogen, Carlsbad, CA, USA), and RNA integrity was verified (2100 Bioanalyzer, Bio Sizing software version A.02.12 SI292; Agilent Technologies, Santa Clara, CA, USA). RNA samples (1 $\mu \mathrm{g})$ were reverse-transcribed using oligo $(\mathrm{dT})$ primers (Invitrogen) and quantitative real-time PCR was performed following the manufacturer's instructions using the QuantiTect SYBR Green PCR kit (Qiagen, Valencia, CA, USA) in ABI PRISM 7900HT sequence detection systems (Applied Biosystems, Foster City, CA, USA). Each transcript in each sample was assayed three times and the fold change ratios between experimental and control samples were calculated relative to $\beta$-actin. Primers were the following: IGF-1: forward 5'-GGCATTGTGGATGAGTGTTG and reverse 5'TCTCCTTTGCAGCTTCGTTT; 179-bp IGFBP-3: forward 5'-ATTCCAAGTTCCATCCACTC and reverse 5'-AGGAGAAGTTCTGGGTGTC; 119-bp ALS forward 5'-CCTGCAGAATCTCTACCATCT and reverse 5'-CAAACTGAGTGAAGCCAGAC; 99-bp receptor activator of nuclear factor-кB ligand (RANKL) forward 5'-GCTCCGAGCTGGTGAAGAAA and reverse 5'-CCCCAAAGTACGTCGCATCT; 82-bp osteocalcin: forward 5'-CGC CTA CAA ACG CAT CTA TG and reverse 5'-AGC TGC TGT GAG ATC CAT AC; and osteoprotegerin (OPG) forward 5'-AGT CGG TGA AGC AGG AGT and reverse:5'-CCA TCT GGA CAT TTT TTG CAA A.

\section{Statistical analysis}

Differences in morphological, growth, and cell behaviorrelated trait values were assessed by ANOVA followed by Tukey's post hoc multiple comparison tests (GraphPad Software Inc., San Diego, CA, USA). Evaluations of hormonal status and IGFBPs were determined by two-way ANOVA or $t$ test (as indicated) using SigmaStat software (SPSS Inc., Chicago, IL, USA). Values are presented as means \pm SE. $P<0.05$ was considered statistically significant.

\section{RESULTS}

\section{Generation of mice with serum IGF-1 deficiency}

Previously established LID, ALSKO, and BP3KO mice were used to generate a series of double mutant progeny strains as well as a triple mutant (LAB) strain.

The crossing strategy was as follows. LID mice are homozygous for floxed IGF-1 and for the Cre recombinase transgene. ALSKO and BP3KO mice contain two null alleles for als and $i g f b p-3$ genes, respectively. The Als wild-type allele is labeled $A$ and the null allele is labeled $a$; similarly, igfbp-3 wild-type and null alleles are labeled $B$ and $b$, respectively. We introduced homozygous floxed IGF-1 alleles (LL) into both BP3KO and ALSKO mice before crossing with LID mice to assure uniformity of IGF-1 expression in all progeny.

Initial crosses between LID and both ALSKO and BP3 parental mice yielded heterozygotes for all genotypes (except those for floxed IGF-1, which were homozygous in all cases). LID/ALSKO heterozygotes (with genotype $\mathrm{L} / \mathrm{L} \mathrm{A} / \mathrm{a} \mathrm{B} / \mathrm{B} \mathrm{Cre}^{+/-}$) and LID/BP3 heterozygotes (with genotype $\mathrm{L} / \mathrm{L} \mathrm{A} / \mathrm{A} \mathrm{B} / \mathrm{b} \mathrm{Cre}^{+/-}$) were crossed, and triple heterozygote progeny (genotype $\mathrm{L} / \mathrm{L} \mathrm{A} / \mathrm{a} \mathrm{B} / \mathrm{b} \mathrm{Cre}^{+/-}$) were selected. Crossing these triple heterozygotes yielded several $\mathrm{F} 2$ genotypes, of which five (shown below) were selected for characterization: control (genotype L/L A/A B/B $\mathrm{Cre}^{-/-}$), LID (genotype L/L A/A B/B $\mathrm{Cre}^{+/-}$or $\mathrm{Cre}^{+/+}$), ALSKO (genotype L/L a/a B/B $\mathrm{Cre}^{-/-}$), BP3KO (genotype $\mathrm{L} / \mathrm{L} \mathrm{A} / \mathrm{A} \mathrm{b} / \mathrm{b} \mathrm{Cre}^{-/-}$), and $L A B$ (genotype $\mathrm{L} / \mathrm{L}$ $\mathrm{a} / \mathrm{a} \mathrm{b} / \mathrm{b} \mathrm{Cre} \mathrm{Cr}^{+/-}$or $\left.\mathrm{Cre}^{+/+}\right)$.

Strains carrying the Cre transgene (LID and LAB) may have single or double integration sites. This did not affect $i g f-1$ gene recombination, based on very small variations in serum IGF-1 in those groups. 
Effects of $a l s$ and $i g f b p-3$ gene inactivation on serum levels of IGF-1 and IGF-1 binding complexes

Chemotypic analysis of serum from LID, ALSKO, $\mathrm{BP} 3 \mathrm{KO}$, and $\mathrm{LAB}$ mice was performed at 4,8 , and $16 \mathrm{wk}$ of age in both males and females. Figure $1 A$ shows data from 8-wk-old males; similar patterns were observed in both males and females at 4 and $16 \mathrm{wk}$.

IGF-1 gene deletion in liver resulted in an $80 \%$ reduction in total serum IGF-1, whereas ALS and IGFBP-3 deletions produced 60 and $40 \%$ reductions, respectively (Fig. 1A). In contrast, LAB mice had virtually undetectable circulating IGF-1 (2.5\% of control). In agreement with previous findings $(18,21,22)$, LID mice showed a 3-fold increase in serum GH; LAB mice, with even greater reductions in serum IGF-1, showed a 6-fold increase (Fig. $1 B$ ). Also as previously seen, GH in both ALSKO and BP3KO mice did not differ from controls despite substantial reductions in serum IGF-1. It is as yet unclear why ALSKO and BP3KO mice do not show an increase in GH secretion. However, these data suggest that a threshold level of serum IGF-1 may be required to prevent increases in $\mathrm{GH}$ expression and that reductions seen in the ALSKO and BP3KO mice have not yet achieved that threshold. ALS levels in serum, which are largely regulated by $\mathrm{GH}$, were increased 7 -fold in LID mice over controls. In addition, BP3KO mice demonstrated a 3-fold increase in serum ALS, despite no detectable increase in serum GH (Fig. $1 C)$. The reductions in serum IGF-1 levels in LID mice were accompanied by a $50 \%$ decrease in serum IGFBP-3 (Fig. 1D). This change was probably due to increased degradation and/or clearance, because IGFBP-3 mRNA levels in livers of control and LID mice did not differ (Fig. 1E). However, establishing these possibilities conclusively will require more extensive pharmacokinetic analyses. ALSKO mice exhibited a $97 \%$ reduction in serum IGFBP-3, also with no change in liver IGFBP-3 mRNA (Fig. $1 E$ ). These findings suggest that ALS is important in stabilizing IGFBP-3 in serum.

We also examined the ability of serum from mutant mouse strains to support formation of ternary complexes with ${ }^{125}$ I-IGF-1 (48). This assay provides qualitative data of all three components routinely seen in serum IGF-1 binding complexes (IGF-1, an IGFBP, and ALS). No ternary complexes (fraction A) were observed in sera of ALSKO or LAB mice (Fig. $1 F$ ). However, sera of ALSKO or LAB mice did show the ability to form binary complexes (fraction B). It is important to note that in this in vitro assay the concentrations of IGF-1 are high enough to saturate the binding capacity of the serum samples, which in LAB mice is due to IGFBP-1, -2 , and -4 . In addition, in this vitro binding assay, the constituents are probably less susceptible to proteolytic degradation than they are in vivo. Surprisingly, serum IGF-1 ternary complex levels in BP3KO mice were similar to those of controls, suggesting that other binding proteins (possibly IGFBP-5) were increased to compensate for the reduced IGFBP-3. Ternary complex formation was similar in LID and control mice. However, in LID mice, there is still a sufficient amount of IGFBP-3 in serum to allow formation of ternary complexes.
A

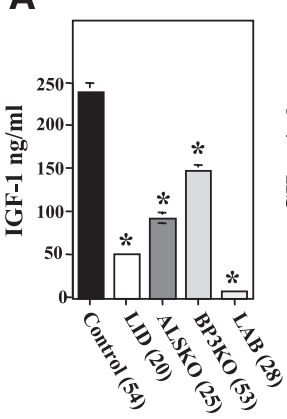

B

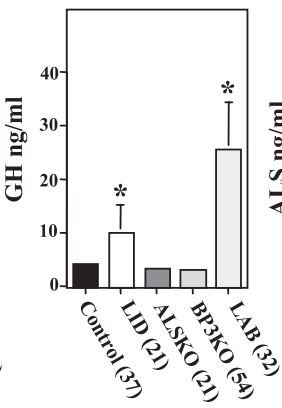

$\mathbf{F}$

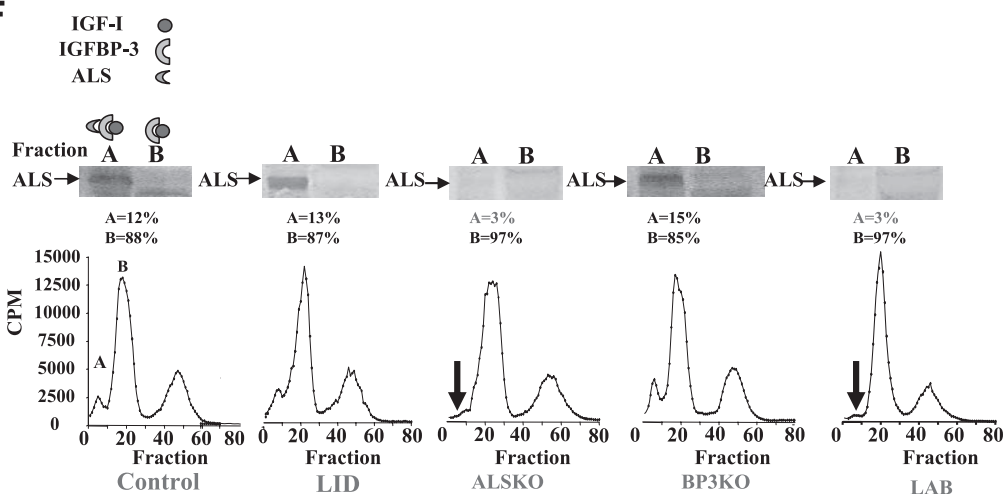

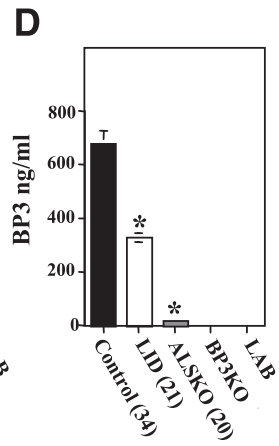

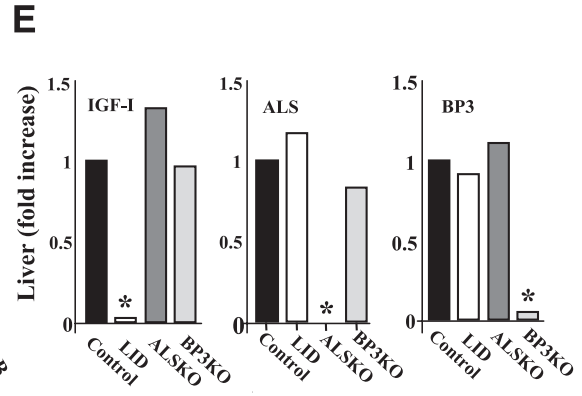

Figure 1. Serologic characterization of IGF-1 deficient mice. A) Serum IGF-1. B) GH. C) ALS. D) IGFBP-3. Sera were obtained from 8- to 10-wk-old control, LID, ALSKO, BP3KO, and LAB mice. Data are means $\pm \mathrm{SE}$; values in parentheses indicate number of mice per group. E) Liver expression of $i g f-1$, als, and $i g f b p-3$ genes was assessed by real-time PCR. ${ }^{*} P<0.05$; twoway ANOVA. $F$ ) Ternary IGF complex-formation was assessed in sera obtained from control, LID, ALSKO, BP3KO, and LAB mice. Sera were incubated overnight at $22^{\circ} \mathrm{C}$ with $\left[{ }^{125} \mathrm{I}\right] \mathrm{IGF}-1$ and then cross-linked with disuccinimidyl suberate and fractionated on HiPrep 16/60 Sephacryl S-200 HR columns. Fractions were collected and counted, and Western immunoblots were used to detect the ALS protein in fractions A and B. Data represent mean cpm; 3-5 mice/group. 


\section{Possible compensatory mechanisms in serum IGF-1 deficiency states}

Changes in serum levels of total IGF-1 and ternary complexes were reflected in altered clearance of radiolabeled IGF-1 (Fig. 2A). The half-life of ${ }^{125}$ I-IGF-1 was the same in LID mice and controls but was significantly reduced in ALSKO, BP3KO, and LAB mice, confirming previous observations that ALS and IGFBP-3 both contribute to the stability of circulating IGF-1.

IGFBP-3 is the most abundant binding protein in serum; however, other binding proteins probably contribute to IGF-1 stability. Assessment of the IGF-1 binding capacity of sera from the different mouse mutants using ${ }^{125}$ I-IGF-1 ligand blot assays revealed overall reductions in IGFBPs in the serum of IGF-1-deficient mice (Fig. 2B). Specifically, IGFBP-3 was reduced in ALSKO and LID mice and, as expected, abolished in BP3KO and LAB mice. IGFBP-2, the second most abundant form of IGFBP in serum, was also reduced in LID, ALSKO, and LAB mice, a finding confirmed by RIA (Fig. 2C). In particular, we found 66, 46, and $76 \%$ reductions in IGFBP-2 levels in LID, ALSKO, and LAB mice, respectively. The large reductions of IGFBP-2 in LID and LAB mice probably reflects suppression by the high GH in those mutants (Fig. 1).

IGFBP-2 concentrations are markedly elevated in response to IGF-1 administration and accompany accelerated growth (35). In addition, IGFBP-2 knockout mice demonstrated normal growth, but altered organ size and increased IGFBP-3 levels, indicating that compensatory mechanisms might increase production of other binding proteins (35). However, we observed that serum levels of IGFBP-2 were reduced, coinciding with accelerated clearance/reduced stability of IGF-1 (Fig.
$2 A$ ), so a compensatory role for IGFBP-2 in IGFBP-3 deficiency is unlikely.

IGFBP-5, which like IGFBP-3, also forms ternary complexes with IGF-1 and ALS $(5,36)$, is normally low in serum and was not detectable by ligand blot (Fig. $2 B)$. However, IGFBP-5 can specifically bind to ALS, even in the presence of higher concentrations of IGFBP-3 (37). IGFBP-5 can either potentiate IGF-1 tissue effects when bound to extracellular matrix (38, $39)$ or inhibit IGF-1 in other circumstances $(40,41)$. Furthermore, the 22-kDa fragment of IGFBP-5 is a potent growth stimulant independent of its ability to bind IGF-1 (38). Western immunoblotting (Fig. 2D) quantified by densitometry (Fig. 2E) revealed 3-fold decreases in IGFBP-5 in ALSKO and LAB mice, suggesting that the stability of IGFBP-5, like that of IGFBP-3, also depends on ALS. In contrast, serum IGFBP-5 in BP3KO mice was almost doubled, suggesting increased stability from increased ALS or some compensatory mechanism. Taken together, the results identify IGFBP-3 and ALS, with lesser contributions from IGFBP-5 and possibly other factors, as elements of an integrated IGF system needed to preserve a normal reservoir of IGF-1 in serum.

\section{Tissue expression of IGF-1, IGFBP-3, and ALS genes in IGF-1 deficiency states}

Although mutant mice exhibited substantial differences in serum levels of IGF-1 and its binding proteins, expression of these constituents in tissues was largely unaffected (Fig. 3). In bone, bone marrow, gonadal fat pad, and muscle, none of the mutants showed altered expression of IGF-1. Moreover, expression of IGFBP-3
A

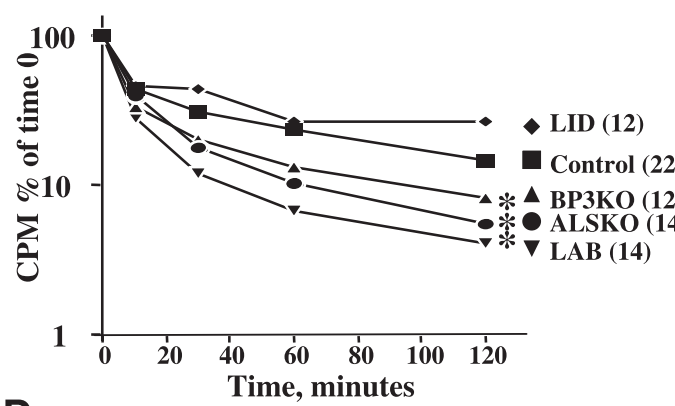

D

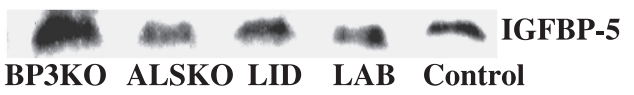

B

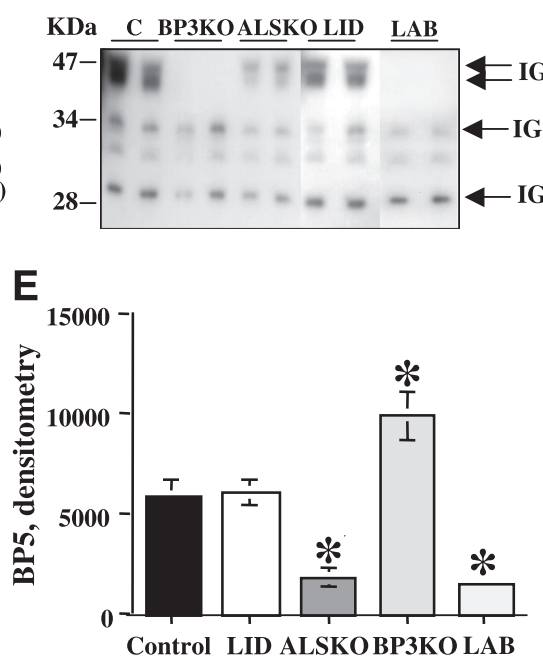

C

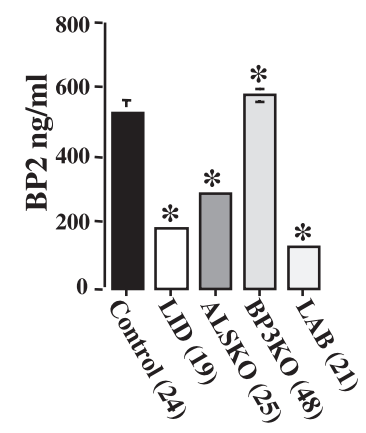

Figure 2. IGF-binding proteins and IGF-1 clearance. A) Half-life of $\left[{ }^{125} \mathrm{I}\right] \mathrm{IGF}-1$ in sera obtained from control, LID, ALSKO, and BP3KO mice. Data are means $\pm \mathrm{sE} ; n$

$>12$ mice/group. $* P<0.05$ ws. control. B) Ligand blot assay shows IGF-1 binding capacity of serum from control, LID, ALSKO, BP3KO, and LAB mice. Reactive bands corresponding to IGFBP-3 were not detectable in BP3KO and LAB mice and significantly reduced in LID and ALSKO mice. C) Serum IGFBP-2 levels, determined by RIA in sera from 8- to 10-wk-old control, LID, ALSKO, BP3KO, and LAB mice. Data are means \pm sE (number per group in parentheses). $D$ ) Serum levels of IGFBP-5 detected by Western immunoblot and $(E)$ quantified by densitometry, showing twofold increase in BP3KO mice. Data are mean \pm sE; $n=5$ /group. 
Figure 3. Tissue expression of $i g f-1, i g f b p-3$, and als. PCR analysis of RNA from femoral diaphyses, bone marrow, gonadal fat pad, and muscle. For primers; see Materials and Methods. Each lane represents a single mouse.

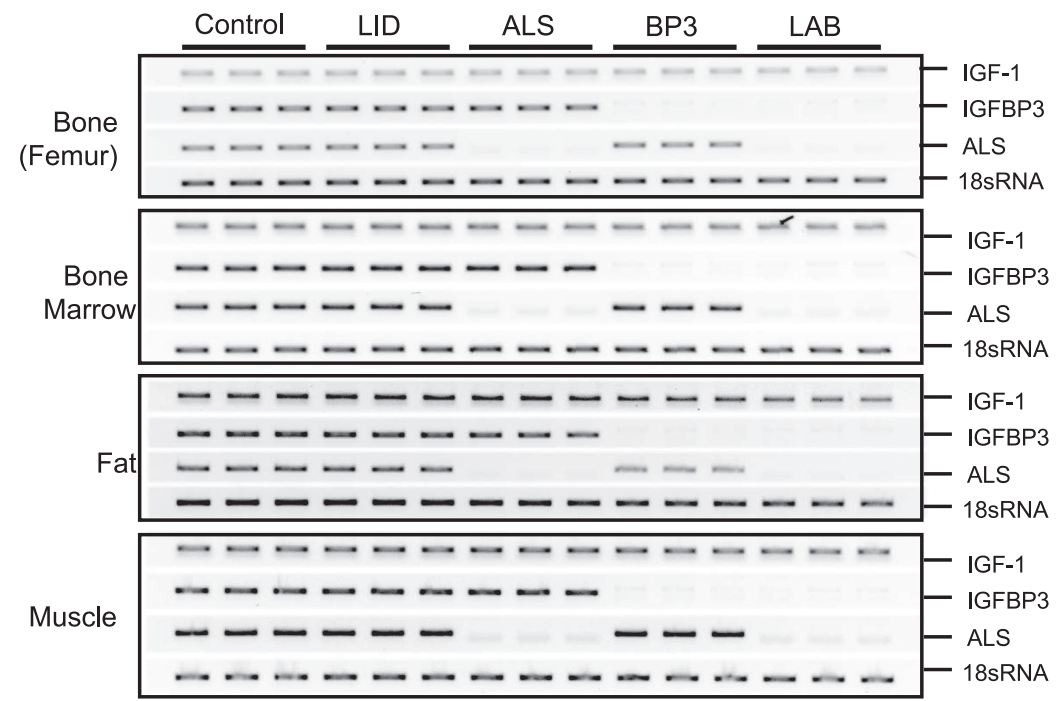

and ALS in all tissues examined was unchanged from that of controls except when that gene had been ablated. We also found that IGF-2 was not expressed in any mutant mouse strain (data not shown). Nonetheless, it is important to note that expression of IGFBP-3 or ALS in other nonskeletal extrahepatic tissues may affect skeletal metabolism indirectly. For instance, LID mice are known to have small spleens (18), and we have recently identified hematopoietic alterations (reductions in $\mathrm{B}$ and $\mathrm{T}$ cells and monocytes) that could affect skeletal development and remodeling (42) (S. Yakar, in preparation).

\section{Postnatal growth in IGF-1 deficiency states}

To relate changes in serum IGF-1 and its binding complexes to its physiological consequences, we first evaluated growth of LID, ALSKO, BP3KO, and LAB mice between 3 and 8 wk of age on the basis of body weight, length, and composition (Fig. 4). As observed previously, body weight of LID mice did not differ significantly from that of controls (Fig. 4A). BP3KO mice, however, showed accelerated growth and at $8 \mathrm{wk}$ were $15-20 \%$ heavier than control mice. This finding differs from that of Ning et al. (23) and may reflect either the floxed IGF-1 allele in the BP3KO mice used in this study or other more general differences between the strains. In contrast, body weights of ALSKO and $\mathrm{LAB}$ mice were 15-20\% lower than those of controls at all ages. Interestingly, weights of LAB and ALSKO mice were comparable, despite much lower serum IGF-1 in $\mathrm{LAB}$ mice, suggesting that igf $b p-3$ gene inactivation may promote growth even in the absence of ALS.

Body lengths in 8-wk-old males were consistent with body weights: ALSKO mice were $8 \%$ shorter than controls, BP3KO mice were $5 \%$ longer, and LID mice were no different (Fig. $4 B$ ). Interestingly, despite undetectable serum IGF-1, LAB mice exhibited only a $6 \%$
A

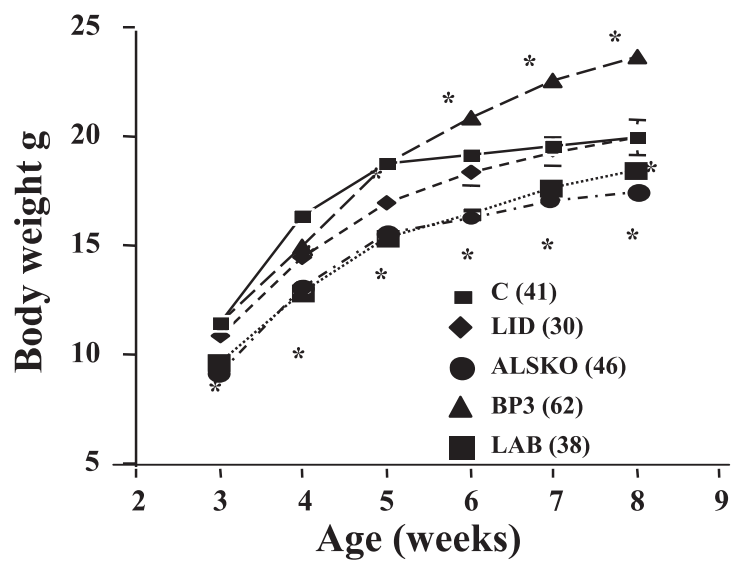

B

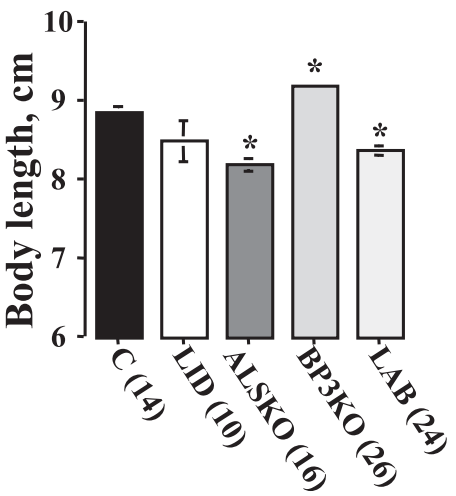

C

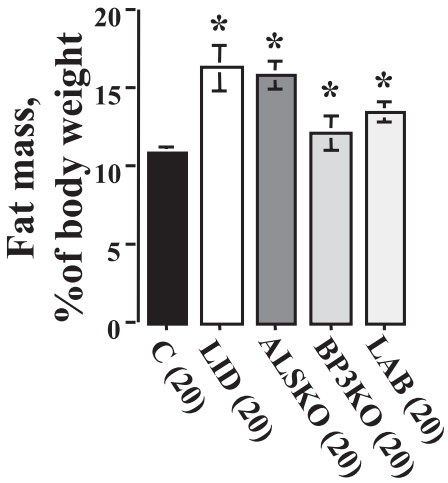

Figure 4. Growth characteristics of IGF-1-deficient mice. $A, B)$ Body weight $(A)$ and body length $(B)$ at 8 wk of age in IGF-1-deficient mice. $C$ ) Body compositions determined by MRI, presented as a percentage of fat mass. Data are means \pm SE; values in parentheses indicate number of mice per group. 
decrease in body length, comparable to that of ALSKO mice that had roughly 10-fold greater serum IGF-1 levels. These data further suggest that $i g f b p-3$ gene inactivation leads to increased body size.

Body composition was assessed by measuring absolute organ and tissue weights and by MRI. All mutant mice exhibited increased adiposity (Fig. 4C). Gonadal fat pad weight was also markedly increased in all IGF-1deficient mice, most notably in LID mice (Table 1).

\section{Adult skeletal phenotype in IGF-1 deficiency states}

The consequences of serum IGF-1 deficiency on skeletal development were assessed by microcomputed tomography analysis of both trabecular and cortical bone in femurs of adult (16-wk-old) male mice (Table 2). Trabecular (BV/TV) was only mildly reduced in LID and LAB mice (10\%) compared with controls and decreased by an additional 10 and $20 \%$ in ALSKO and BP3KO mice, respectively. Trabecular number and separation exhibited patterns similar to $\mathrm{BV} / \mathrm{TV}$, whereas only BP3KO mice differed from controls in trabecular thickness, showing an increase. In cortical bone, mid-diaphyseal thickness decreased in LID and LAB mice only. Cross-sectional geometry (i.e., polar moment of inertia), an indirect measure of bone strength, was decreased significantly in LID, ALSKO, and $\mathrm{LAB}$ mice but unchanged in BP3KO mice. The most profound effect on cortical bone was seen in LAB mice, which exhibited a $10 \%$ decrease in thickness and a 2-fold decrease in polar moment of inertia. In summary, cortical bone parameters appeared to be highly dependent on serum IGF-1 levels, whereas trabecular BV/TV was affected more by changes in the distribution of IGF binding complex constituents.

\section{Indices of bone resorption and formation in IGF-1 deficiency states}

Differences in skeletal mass and organization may arise from altered bone formation, bone resorption, or both. To assess possible differences in tissue levels of bone remodeling regulators, we tested femoral diaphyseal bone (after removal of bone marrow) for the expression of RANKL and its decoy receptor OPG (Fig. 5).
RANKL is essential for osteoclast differentiation, and the OPG/RANKL ratio is considered an index of bone resorption activity both in vivo and in vitro. RANKL expression was reduced relative to controls in LID and ALSKO mice, but increased 6-fold in BP3KO and 3-fold in $\mathrm{LAB}$ mice, respectively. On the other hand, OPG expression was undetectable in BP3KO and LAB mice, respectively. Consequently, LID and ALSKO mice exhibited highly increased OPG/RANKL ratios (40- to 50 -fold), suggesting overall reduced bone resorption in these mutant strains.

\section{Indices of carbohydrate metabolism in IGF-1 deficiency states}

Adult (14-16 wk) mice of all strains appeared normoglycemic in the fasting state (data not shown). However, LID and LAB mice exhibited increased serum insulin levels (Fig. 6A), probably due to increases in GH and secondary insulin resistance. Increased serum leptin was observed in all strains (Fig. 6B), in agreement with our previous observation of increased adiposity in LID, ALSKO, and LAB mice but only a $10 \%$ increase in fat in the BP3KO mice. Glucose tolerance tests, reflecting both $\beta$-cell function and insulin sensitivity, revealed increased glucose clearance in ALSKO mice and reduced clearance in LID and LAB mice (19, 20, 22) (Fig. $6 C$ ). LAB mice (which also have increased serum GH and insulin) exhibited higher blood glucose levels than controls at 30 and $60 \mathrm{~min}$ after glucose load, but cleared glucose efficiently after $120 \mathrm{~min}$. These data suggest that the prevalence of IGF-1 complexes in serum and/or in tissues produces different effects on $\mathrm{GH}$ secretion and carbohydrate metabolism. As we noted previously for skeletal effects, changes in expression and bioactivity of IGFBP-3 in extrahepatic tissues can affect carbohydrate metabolism. For example, IGFBP3 is expressed within islet cells throughout fetal and neonatal life and is mainly associated with the $\alpha$-cell-rich islet mantle (43). In vitro studies show that $\beta$-islet cell lines also express the IGFBP-3 gene, raising the possibility that changes in IGFBP3 expression can directly or indirectly affect insulin secretion and action in peripheral tissues (44-47).

TABLE 1. Organ weights at 8 wh of age

\begin{tabular}{|c|c|c|c|c|c|}
\hline Body weight (g) & $19.04 \pm 0.6$ & $19.58 \pm 0.45^{\#, \$}$ & $16.8 \pm 0.25^{*, \dagger, \#}$ & $23.0 \pm 0.42^{*, \dagger, \#}$ & $17.9 \pm 0.4^{*,+, \$}$ \\
\hline Body length $(\mathrm{cm})$ & $8.8 \pm 0.02$ & $8.5 \pm 0.28^{*, \$, @ ~}$ & $8.2 \pm 0.07 * \$$ & $9.2 \pm 0.06^{*,+, \#, @ ~}$ & $8.3 \pm 0.06^{*}, \$$ \\
\hline Spleen (g) & $0.06 \pm 0.00$ & $0.04 \pm 0.00^{*, \#, \$}$ & $0.05 \pm 0.00^{*,+, \$, @ ~}$ & $0.08 \pm 0.00^{*,+, \#, @ ~}$ & $0.04 \pm 0.00^{*, \#, \$}$ \\
\hline Kidney (g) & $0.26 \pm 0.01$ & $0.26 \pm 0.00$ & $0.3 \pm 0.00$ & $0.3 \pm 0.00$ & $0.26 \pm 0.00$ \\
\hline Liver $(\mathrm{g})$ & $0.88 \pm 0.04$ & $0.97 \pm 0.04^{*, \#}$ & $0.86 \pm 0.02^{\dagger, \#}$ & $1.16 \pm 0.04^{*,+, \#, @ ~}$ & $0.93 \pm 0.03^{*, \#, @ ~}$ \\
\hline
\end{tabular}

Data are means $\pm \mathrm{se} . * P>0.05$ vs. control; ${ }^{\dagger} P>0.05$ vs. LID; ${ }^{*} P>0.05$ vs. ALSKO; ${ }^{\$} P>0.05$ vs. BP3KO; ${ }^{\circledR} P>0.05$ vs. LAB. 


\begin{tabular}{|c|c|c|c|c|c|}
\hline Variable & Control $(n=13)$ & LID $(n=8)$ & ALSKO $(n=7)$ & BP3KO $(n=13)$ & $\mathrm{LAB}(n=8)$ \\
\hline Trabecular BV/TV (\%) & $17.42 \pm 1.06$ & $15.56 \pm 0.76^{\$}$ & $15.088 \pm 1.38^{\$}$ & $11.80 \pm 0.82^{*, \dagger, \#, @ ~}$ & $15.98 \pm 0.93^{\$}$ \\
\hline Trabecular number $\left(\mathrm{mm}^{-1)}\right.$ & $4.98 \pm 0.14$ & $4.67 \pm 0.08^{\#, \$}$ & $4.01 \pm 0.31 *,+, @$ & $3.65 \pm 0.16^{*,+, @ ~}$ & $5.03 \pm 0.16^{\#, \$}$ \\
\hline Trabecular thickness $(\mu \mathrm{m})$ & $50.3 \pm 1.9$ & $47.8 \pm 0.7^{\$}$ & $49.0 \pm 1.2^{\$}$ & $54.01 \pm 2.3^{\dagger, @ ~}$ & $47.9 \pm 1.1^{\$}$ \\
\hline Trabecular separation $(\mu \mathrm{m})$ & $200.36 \pm 7.2$ & $212.3 \pm 4.4^{\#, \$}$ & $262.3 \pm 23.6^{*,+, @ ~}$ & $280.9 \pm 12.10^{*, \dagger, @ ~}$ & $197.4 \pm 7.9^{\#, \$}$ \\
\hline Cortical bone area/total area $(\%)$ & $46.64 \pm 0.74$ & $47.16 \pm 0.69$ & $51.21 \pm 0.91$ & $48.78 \pm 0.88$ & $48.32 \pm 0.91$ \\
\hline Cortical bone area $\left(\mathrm{mm}^{2)}\right.$ & $0.68 \pm 0.63$ & $0.55 \pm 0.02$ & $0.58 \pm 0.01$ & $0.69 \pm 0.02$ & $0.49 \pm 0.01$ \\
\hline Cortical thickness $(\mu \mathrm{m})$ & $181.8 \pm 5.0$ & $166.7 \pm 3.8^{*, \#, \$}$ & $180.0 \pm 1.9^{\dagger, @ ~}$ & $188.2 \pm 4.1^{\dagger, @ ~}$ & $160.7 \pm 2.9^{*, \#, \$}$ \\
\hline Polar moment of inertia $\left(\mathrm{mm}^{4}\right)$ & $0.27 \pm 0.02$ & $0.17 \pm 0.01 * \$, \$$ & $0.17 \pm 0.01 *, \$, @$ & $0.26 \pm 0.01^{\dagger, \#, @ ~}$ & $0.12 \pm 0.00^{*, \dagger, \#, \$}$ \\
\hline
\end{tabular}

Data are mean $\pm \mathrm{sE} .{ }^{*} P>0.05$ vs. control; ${ }^{\dagger} P>0.05$ vs. LID; ${ }^{\#} P>0.05$ vs. ALSKO; ${ }^{\$} P>0.05$ vs. BP3KO; ${ }^{\circledR} P>0.05$ vs. LAB.

\section{DISCUSSION}

Two major problems in understanding the functions of IGF-1 are its dual roles as an endocrine and autocrine/ paracrine effector and the possible functions of its several binding proteins in controlling bioavailability. In this study we compared the phenotypes of genetically deficient mice lacking liver-specific expression of IGF-1 (LID), ALS, and IGFBP-3, as well as a triple knockout that resulted in a reduction of total serum IGF-1 levels by $>97 \%$. Our results indicate that locally produced IGF-1 predominates over circulating IGF-1 in maintaining skeletal integrity and that IGF-1 binding complex constituents (ALS and IGFBP-3) also play crucial roles in regulating skeletal function.

The severe skeletal phenotype resulting from complete knockout of IGF-1 indicates critical roles for IGF-1 in skeletal development and maintenance. Subsequent attempts to eliminate circulating IGF-1 by genetic ablation of individual binding complex components (liverspecific IGF-1, ALS, and IGFBP-3), only partly reduced serum IGF-1 and yielded minor skeletal phenotypes, suggesting that the remaining serum IGF-1 could still have had a substantial impact on the skeleton. Here we show that combined ablation of liver IGF-1, ALS, and IGFBP-3 removed $>97 \%$ of total serum IGF-I; the remaining $\sim 2.5 \%$ corresponds to the amount of free IGF-1 commonly detected in serum. Moreover, serum from the triple knockout mouse (LAB) had reduced levels of other binding proteins (IGFBP-2 and IGFBP-5) and exhibited no ability to form complexes with exogenous IGF-1. These results indicate a low likelihood of IGF-1 complexes with other binding proteins in serum.
However, IGF-1 in tissues can still complex with other binding proteins, and these complexes may help define local IGF-1 bioavailability.

LAB mice exhibited a clear bone phenotype, including reduced cross-sectional area (greater slenderness) and cortical area and a 2-fold reduction in polar moment of inertia relative to controls. However, these phenotypic features were still markedly less severe than those reported for IGF-1-null mice (48), strongly suggesting that tissue (local) IGF-1 and its complexes and not circulating IGF-1 have a major role in skeletal development. Interestingly, reductions in linear growth of LID and LAB mice (25\%) were apparent despite increases in circulating $\mathrm{GH}$, which promotes linear growth in bone by stimulating local IGF-1 production. Thus, elevated GH was not sufficient to compensate for the serum IGF-1 deficiency.

Disruption of IGF binding complexes in ALSKO, BP3KO, and LAB mice did not substantially increase other IGFBPs, suggesting the lack of a compensatory mechanism to maintain levels of IGF complexes in serum. Whether such compensatory mechanisms exist in individual tissues, however, remains to be determined. There is no evidence that tissue complexes are derived from serum-borne constituents, so individual IGFBPs/ALS are likely to be produced locally.

Whether free or binary-complexed IGF-1 is the predominantly active form in tissue is not clear nor are the mechanisms of IGF-1 release from its complexes. Furthermore, IGFBPs can not only potentiate or inhibit IGF-1 action but have also been reported to regulate cell migration, proliferation, and apoptosis independent of IGF $(5,6)$. Transgenic mice overexpressing
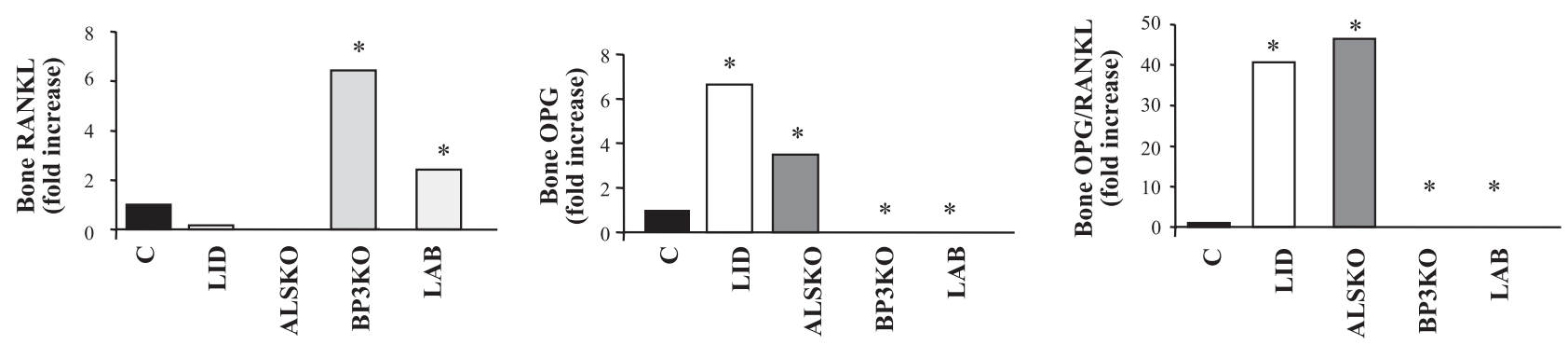

Figure 5. Bone resorption and formation indices. Rankl and opg expression in femoral diaphysis (real-time PCR). For primers, see Materials and Methods. Data are means $\pm \mathrm{sE} ; n=5 \mathrm{mice} /$ group. 



Figure 6. $A, B$ ) Carbohydrate metabolism indices serum insulin $(A)$ and leptin $(B)$ analyzed in the fed state (RIA). Data are means $\pm \mathrm{sE} ; n>10 \mathrm{mice} /$ group. C) Glucose tolerance. Glucose $(2 \mathrm{mg} / \mathrm{kg})$ injected intraperitoneally into 6 -h fasted mice; blood glucose measured at indicated time points. Data are means $\pm \mathrm{SE} ; n=6-8 \mathrm{mice}$ /group.

IGFBP-3 were growth-retarded (27), probably because of reduced IGF-1 bioavailability. Similarly, histomorphometric studies of IGFBP-3 overexpressors showed increased indices of bone resorption and decreased indices of bone formation (49-52). Our findings that BP3KO mice showed increases in body mass, linear growth, and cortical thickness support the concept that IGFBP-3 has a growth-inhibitory role independent of IGF-1. Yet, IGFBP-3 ablation did not influence the skeleton uniformly, as trabecular $\mathrm{BV} / \mathrm{TV}$ declined in BP3KO mice.

The finding that altered levels of IGF and its binding complexes produced distinct effects on the growth plate and on cortical, and trabecular bone was particularly interesting; however, several hormones (e.g., parathyroid hormone and estrogen) have long been known to exert compartment-specific effects on bone (53-55). The mechanistic basis for these results is not yet clear but probably involves differences in the cellular and biochemical microenvironment (e.g., marrow, vascularity, and adiposity) and state of mechanical loading. Furthermore, whether these differences can eventually be linked to specific sites of fracture risk (e.g., spine or hip) remains to be determined.

Previous human studies established significant correlations between serum IGF-1 levels and BMD and have defined serum IGF-1 as a risk factor for osteoporotic fractures (56-59). However, these studies have been limited in two ways. First, IGF-I measurements reflected only total serum levels, and second, BMD measurements provided only tissue average assessments of bone density and did not reflect changes in individual skeletal compartments. In the current study, we confirm that changes in serum IGF-1 levels can profoundly affect bone microarchitecture, but our data further demonstrate that changes in the levels of IGF-1 and its complexes have distinct effects on cortical and trabecular bone. Moreover, our findings clearly demonstrate that total IGF-1 levels in serum may not be an accurate predictor of skeletal responses to perturbations in IGF-1. Rather, the distribution of IGF-1 among specific complexes, both in serum and in tissues, is likely to play a dominant role in defining the effects of IGF-I on the skeleton.

Human mutations of the GH-IGF system demonstrate that IGF-1 is critical for normal human growth. The absence of IGF-1 or its receptor results in phenotypes that vary between mice and humans with respect to their effects on metabolism and brain development in addition to growth. In humans, loss of the ALS gene as described in 11 patients already $(9,33,60-64)$, although resulting in a dramatic reduction in serum IGF-1, leads to a minimal growth phenotype (as seen in the ALSKO mouse). These patients present with normal stimulated GH levels with marked reduction of IGF-1 and IGFBP-3 levels and patients manifest delayed puberty, delayed bone mineralization, and few or no metabolic or neurological effects. Although this difference from the mouse phenotype has not been fully explained, it has been suggested that the likely increase in the IGF-1 flux into tissues may be the reason for the interspecies differences. Our study demonstrates that the three components of the circulating IGF-1 complex have multifaceted additive roles on the metabolic and growth-promoting actions of IGF-1. Although a human mutation in any of the IGFBPs has yet to be described, our findings suggest what the human phenotype may look like if such an individual exists.

In conclusion, we have demonstrated the importance of the circulating IGF regulatory complex in defining skeletal status. Moreover, we have shown that total serum IGF-1 cannot predict bone acquisition, but that each component of the IGF complex serves an important role in bone growth and maintenance as well as in carbohydrate metabolism. Evaluation of IGF-1 actions as part of a global system (with binding proteins and the ALS), rather than as a single peptide, would provide critical new information regarding the role of serum IGF-1 in normal physiology and disease.

This work was funded by the National Institutes of Health (AR054919-01A, 1R01AR055141-01, and AR45433). We thank 
Dr. Christopher Price for assistance with histomorphometric analysis, Kristy VanDervoot for her effort in maintaining the mouse colonies. and genotyping, and Liliana Karabatas (Gutierrez Children's Hospital, Buenos Aires, Argentina) for technical assistance in determination of IGF-1 complex formation.

\section{REFERENGES}

1. Trejo, J. L., Carro, E., and Burks, D. J. (2005) Experimental models for understanding the role of insulin-like growth factor-I and its receptor during development. Adv. Exp. Med. Biol. 567, $27-53$

2. Adamo, M. L., Neuenschwander, S., LeRoith, D., and Roberts, C. T., Jr. (1993) Structure, expression, and regulation of the IGF-I gene. Adv. Exp. Med. Biol. 343, 1-11

3. Umayahara, Y., Ji, C., Centrella, M., Rotwein, P., and McCarthy, T. L. (1997) CCAAT/enhancer-binding protein $\delta$ activates insulin-like growth factor-I gene transcription in osteoblasts. Identification of a novel cyclic AMP signaling pathway in bone. J. Biol. Chem. 272, 31793-31800

4. Wang, L., Wang, X., and Adamo, M. L. (2000) Two putative GATA motifs in the proximal exon 1 promoter of the rat insulin-like growth factor I gene regulate basal promoter activity. Endocrinology 141, 1118-1126

5. Mohan, S., and Baylink, D. J. (2002) IGF-binding proteins are multifunctional and act via IGF-dependent and -independent mechanisms. J. Endocrinol. 175, 19-31

6. Baxter, R. C. (2000) Insulin-like growth factor (IGF)-binding proteins: interactions with IGFs and intrinsic bioactivities. Am. J. Physiol. Endocrinol. Metab. 278, E967-E976

7. Boisclair, Y. R., Hurst, K. R., Ueki, I., Tremblay, M. L., and Ooi, G. T. (2000) Regulation and role of the acid-labile subunit of the 150-kilodalton insulin-like growth factor complex in the mouse. Pediatr. Nephrol. 14, 562-566

8. Boisclair, Y. R., Rhoads, R. P., Ueki, I., Wang, J., and Ooi, G. T. (2001) The acid-labile subunit (ALS) of the $150 \mathrm{kDa}$ IGFbinding protein complex: an important but forgotten component of the circulating IGF system. J. Endocrinol. 170, 63-70

9. Domene, H. M., Bengolea, S. V., Jasper, H. G., and Boisclair, Y. R. (2005) Acid-labile subunit deficiency: phenotypic similarities and differences between human and mouse. J. Endocrinol. Invest. 28, 43-46

10. Silha, J. V., Gui, Y., Modric, T., Suwanichkul, A., Durham, S. K., Powell, D. R., and Murphy, L. J. (2001) Overexpression of the acid-labile subunit of the IGF ternary complex in transgenic mice. Endocrinology 142, 4305-4313

11. Mohseni-Zadeh, S., and Binoux, M. (1997) Insulin-like growth factor (IGF) binding protein-3 interacts with the type 1 IGF receptor, reducing the affinity of the receptor for its ligand: an alternative mechanism in the regulation of IGF action. Endocrinology 138, 5645-5648

12. Ricort, J. M., and Binoux, M. (2001) Insulin-like growth factor (IGF) binding protein-3 inhibits type 1 IGF receptor activation independently of its IGF binding affinity. Endocrinology 142, $108-113$

13. Firth, S. M., and Baxter, R. C. (2002) Cellular actions of the insulin-like growth factor binding proteins. Endocr. Rev. 23, $824-854$

14. Rajaram, S., Baylink, D. J., and Mohan, S. (1997) Insulin-like growth factor-binding proteins in serum and other biological fluids: regulation and functions. Endocr. Rev. 18, 801-831

15. Clemmons, D. R. (2001) Use of mutagenesis to probe IGFbinding protein structure/function relationships. Endocr. Rev. 22, $800-817$

16. Holly, J., and Perks, C. (2006) The role of insulin-like growth factor binding proteins. Neuroendocrinology 83, 154-160

17. Yakar, S., Liu, J. L., Stannard, B., Butler, A., Accili, D., Sauer, B., and LeRoith, D. (1999) Normal growth and development in the absence of hepatic insulin-like growth factor I. Proc. Natl. Acad. Sci. U. S. A. 96, 7324-7329

18. Yakar, S., Rosen, C. J., Beamer, W. G., Ackert-Bicknell, C. L., Wu, Y., Liu, J. L., Ooi, G. T., Setser, J., Frystyk, J., Boisclair, Y. R., and
LeRoith, D. (2002) Circulating levels of IGF-1 directly regulate bone growth and density. J. Clin. Invest. 110, 771-781

19. Yakar, S., Liu, J. L., Fernandez, A. M., Wu, Y., Schally, A. V., Frystyk, J., Chernausek, S. D., Mejia, W., and Le Roith, D. (2001) Liver-specific IGF-1 gene deletion leads to muscle insulin insensitivity. Diabetes 50, 1110-1118

20. Yakar, S., Setser, J., Zhao, H., Stannard, B., Haluzik, M., Glatt, V., Bouxsein, M. L., Kopchick, J. J., and LeRoith, D. (2004) Inhibition of growth hormone action improves insulin sensitivity in liver IGF-1-deficient mice. J. Clin. Invest. 113, 96-105

21. Ueki, I., Ooi, G. T., Tremblay, M. L., Hurst, K. R., Bach, L. A., and Boisclair, Y. R. (2000) Inactivation of the acid labile subunit gene in mice results in mild retardation of postnatal growth despite profound disruptions in the circulating insulin-like growth factor system. Proc. Natl. Acad. Sci. U. S. A. 97, $6868-$ 6873

22. Haluzik, M., Yakar, S., Gavrilova, O., Setser, J., Boisclair, Y., and LeRoith, D. (2003) Insulin resistance in the liver-specific IGF-1 gene-deleted mouse is abrogated by deletion of the acid-labile subunit of the IGF-binding protein-3 complex: relative roles of growth hormone and IGF-1 in insulin resistance. Diabetes 52, 2483-2489

23. Ning, Y., Schuller, A. G., Bradshaw, S., Rotwein, P., Ludwig, T., Frystyk, J., and Pintar, J. E. (2006) Diminished growth and enhanced glucose metabolism in triple knockout mice containing mutations of insulin-like growth factor binding protein-3, -4 , and -5. Mol. Endocrinol. 20, 2173-2186

24. Murphy, L. J., Molnar, P., Lu, X., and Huang, H. (1995) Expression of human insulin-like growth factor-binding protein-3 in transgenic mice. J. Mol. Endocrinol. 15, 293-303

25. Murphy, L. J., Rajkumar, K., and Molnar, P. (1995) Phenotypic manifestations of insulin-like growth factor binding protein-1 (IGFBP-1) and IGFBP-3 overexpression in transgenic mice. Prog. Growth Factor Res. 6, 425-432

26. Schneider, M. R., Lahm, H., Wu, M., Hoeflich, A., and Wolf, E. (2000) Transgenic mouse models for studying the functions of insulin-like growth factor-binding proteins. FASEB J. 14, 629640

27. Modric, T., Silha, J. V., Shi, Z., Gui, Y., Suwanichkul, A., Durham, S. K., Powell, D. R., and Murphy, L. J. (2001) Phenotypic manifestations of insulin-like growth factor-binding protein-3 overexpression in transgenic mice. Endocrinology 142, $1958-1967$

28. Yakar, S., Bouxsein, M. L., Canalis, E., Sun, H., Glatt, V., Gundberg, C., Cohen, P., Hwang, D., Boisclair, Y., Leroith, D., and Rosen, C. J. (2006) The ternary IGF complex influences postnatal bone acquisition and the skeletal response to intermittent parathyroid hormone. J. Endocrinol. 189, 289-299

29. Silha, J. V., Gui, Y., Mishra, S., Leckstrom, A., Cohen, P., and Murphy, L. J. (2005) Overexpression of $\mathrm{Gly}^{56} / \mathrm{Gly}^{80} / \mathrm{Gly}^{81}$. mutant insulin-like growth factor-binding protein-3 in transgenic mice. Endocrinology 146, 1523-1531

30. Imai, Y., Moralez, A., Andag, U., Clarke, J. B., Busby, W. H., Jr., and Clemmons, D. R. (2000) Substitutions for hydrophobic amino acids in the N-terminal domains of IGFBP-3 and -5 markedly reduce IGF-I binding and alter their biologic actions. J. Biol. Chem. 275, 18188-18194

31. Chen, J. W., Hojlund, K., Beck-Nielsen, H., Sandahl Christiansen, J., Orskov, H., and Frystyk, J. (2005) Free rather than total circulating insulin-like growth factor-I determines the feedback on growth hormone release in normal subjects. J. Clin. Endocrinol. Metab. 90, 366-371

32. Baxter, R. C., and Martin, J. L. (1989) Structure of the $M_{r}$ 140,000 growth hormone-dependent insulin-like growth factor binding protein complex: determination by reconstitution and affinity-labeling. Proc. Natl. Acad. Sci. U. S. A. 86, $6898-6902$

33. Domene, H. M., Bengolea, S. V., Martinez, A. S., Ropelato, M. G., Pennisi, P., Scaglia, P., Heinrich, J. J., and Jasper, H. G. (2004) Deficiency of the circulating insulin-like growth factor system associated with inactivation of the acid-labile subunit gene. N. Engl. J. Med. 350, 570-577

34. Bouxsein, M. L., Rosen, C. J., Turner, C. H., Ackert, C. L., Shultz, K. L., Donahue, L. R., Churchill, G., Adamo, M. L., Powell, D. R., Turner, R. T., Muller, R., and Beamer, W. G. (2002) Generation of a new congenic mouse strain to test the relationships among serum insulin-like growth factor I, bone 
mineral density, and skeletal morphology in vivo. J. Bone Miner. Res. 17, 570-579

35. Wood, T. L., Rogler, L. E., Czick, M. E., Schuller, A. G., and Pintar, J. E. (2000) Selective alterations in organ sizes in mice with a targeted disruption of the insulin-like growth factor binding protein-2 gene. Mol. Endocrinol. 14, 1472-1482

36. Mohan, S., and Baylink, D. J. (1991) Bone growth factors. Clin. Orthop. Relat. Res. 263, 30-48

37. Twigg, S. M., Kiefer, M. C., Zapf, J., and Baxter, R. C. (2000) A central domain binding site in insulin-like growth factor binding protein-5 for the acid-labile subunit. Endocrinology 141, $454-457$

38. Jones, J. I., Gockerman, A., Busby, W. H., Jr., Camacho-Hubner, C., and Clemmons, D. R. (1993) Extracellular matrix contains insulin-like growth factor binding protein-5: potentiation of the effects of IGF-I. J. Cell Biol. 121, 679-687

39. Kanatani, M., Sugimoto, T., Nishiyama, K., and Chihara, K. (2000) Stimulatory effect of insulin-like growth factor binding protein- 5 on mouse osteoclast formation and osteoclastic boneresorbing activity. J. Bone Miner. Res. 15, 902-910

40. Butt, A. J., Dickson, K. A., Jambazov, S., and Baxter, R. C. (2005) Enhancement of tumor necrosis factor- $\alpha$-induced growth inhibition by insulin-like growth factor-binding protein-5 (IGFBP-5), but not IGFBP-3 in human breast cancer cells. Endocrinology 146, 3113-3122

41. Butt, A. J., Dickson, K. A., McDougall, F., and Baxter, R. C. (2003) Insulin-like growth factor-binding protein-5 inhibits the growth of human breast cancer cells in vitro and in vivo. J. Biol. Chem. 278, 29676-29685

42. Lorenzo, J., Horowitz, M., and Choi, Y. (2008) Osteoimmunology: interactions of the bone and immune system. Endocr. Rev. 29, 403-440

43. Hill, D. J., Hogg, J., Petrik, J., Arany, E., and Han, V. K. (1999) Cellular distribution and ontogeny of insulin-like growth factors (IGFs) and IGF binding protein messenger RNAs and peptides in developing rat pancreas. J. Endocrinol. 160, 305-317

44. Chen, X., and Ferry, R. J., Jr. (2006) Novel actions of IGFBP-3 on intracellular signaling pathways of insulin-secreting cells. Growth Horm. IGF Res. 16, 41-48

45. De, W., Breant, B., Czernichow, P., and Asfari, M. (1995) Growth hormone $(\mathrm{GH})$ and prolactin (PRL) regulate IGFBP-3 gene expression in rat $\beta$-cells. Mol. Cell. Endocrinol. 114, 43-50

46. Maitra, A., Hansel, D. E., Argani, P., Ashfaq, R., Rahman, A., Naji, A., Deng, S., Geradts, J., Hawthorne, L., House, M. G., and Yeo, C. J. (2003) Global expression analysis of well-differentiated pancreatic endocrine neoplasms using oligonucleotide microarrays. Clin. Cancer Res. 9, 5988-5995

47. Shim, M. L., Levitt Katz, L. E., Davis, J., Dotzler, W. C., Cohen, P., and Ferry, R. J., Jr. (2004) Insulin-like growth factor binding protein-3 is a novel mediator of apoptosis in insulin-secreting cells. Growth Horm. IGF Res. 14, 216-225

48. Liu, J. P., Baker, J., Perkins, A. S., Robertson, E. J., and Efstratiadis, A. (1993) Mice carrying null mutations of the genes encoding insulin-like growth factor I (Igf-1) and type 1 IGF receptor (Igflr). Cell 75, 59-72

49. Silha, J. V., Mishra, S., Rosen, C. J., Beamer, W. G., Turner, R. T., Powell, D. R., and Murphy, L. J. (2003) Perturbations in bone formation and resorption in insulin-like growth factor binding protein-3 transgenic mice. J. Bone Miner. Res. 18, 1834-1841

50. Martin, I., Muraglia, A., Campanile, G., Cancedda, R., and Quarto, R. (1997) Fibroblast growth factor-2 supports ex vivo expansion and maintenance of osteogenic precursors from human bone marrow. Endocrinology 138, 4456-4462

51. Van den Dolder, J., Mooren, R., Vloon, A. P., Stoelinga, P. J., and Jansen, J. A. (2006) Platelet-rich plasma: quantification of growth factor levels and the effect on growth and differentiation of rat bone marrow cells. Tissue Eng. 12, 3067-3073

52. Wang, D. S., Sato, K., Demura, H., Kato, Y., Maruo, N., and Miyachi, Y. (1999) Osteo-anabolic effects of human growth hormone with 22K- and 20K Daltons on human osteoblast-like cells. Endocr. J. 46, 125-132

53. Bouxsein, M. L., Myers, K. S., Shultz, K. L., Donahue, L. R., Rosen, C. J., and Beamer, W. G. (2005) Ovariectomy-induced bone loss varies among inbred strains of mice. J. Bone Miner. Res. 20, 1085-1092

54. Marsell, R., Jonsson, K. B., Cho, T. J., Einhorn, T. A., Ohlsson, C., and Schipani, E. (2007) Mice expressing a constitutively active $\mathrm{PTH} / \mathrm{PTHrP}$ receptor in osteoblasts show reduced callus size but normal callus morphology during fracture healing. Acta Orthop. 78, 39-45

55. Wiren, K. M., Semirale, A. A., Zhang, X. W., Woo, A., Tommasini, S. M., Price, C., Schaffler, M. B., and Jepsen, K. J. (2008) Targeting of androgen receptor in bone reveals a lack of androgen anabolic action and inhibition of osteogenesis: a model for compartment-specific androgen action in the skeleton. Bone 43, 440-451

56. Hedstrom, M., Saaf, M., Brosjo, E., Hurtig, C., Sjoberg, K., Wesslau, A., and Dalen, N. (2004) Positive effects of short-term growth hormone treatment on lean body mass and BMC after a hip fracture: a double-blind placebo-controlled pilot study in 20 patients. Acta Orthop. Scand. 75, 394-401

57. Joseph, C., Kenny, A. M., Taxel, P., Lorenzo, J. A., Duque, G., and Kuchel, G. A. (2005) Role of endocrine-immune dysregulation in osteoporosis, sarcopenia, frailty and fracture risk. Mol. Aspects Med. 26, 181-201

58. Rosen, C. J. (2004) Insulin-like growth factor I and bone mineral density: experience from animal models and human observational studies. Best Pract. Res. Clin. Endocrinol. Metab. 18, 423-435

59. Taniguchi, T., Matsumoto, T., and Shindo, H. (2003) Changes of serum levels of osteocalcin, alkaline phosphatase, IGF-I and IGF-binding protein-3 during fracture healing. Injury 34, 477479

60. Banerjee, I., Hanson, D., Perveen, R., Whatmore, A., Black, G. C., and Clayton, P. E. (2008) Constitutional delay of growth and puberty is not commonly associated with mutations in the acid labile subunit gene. Eur. J. Endocrinol. 158, $473-477$

61. Daughaday, W. H. (2004) Circulating IGF-I deficiency and inactivation of the acid-labile subunit gene. N. Engl. J. Med. 350, 1906

62. Domene, H. M., Martinez, A. S., Frystyk, J., Bengolea, S. V., Ropelato, M. G., Scaglia, P. A., Chen, J. W., Heuck, C., Wolthers, O. D., Heinrich, J. J., and Jasper, H. G. (2007) Normal growth spurt and final height despite low levels of all forms of circulating insulin-like growth factor-I in a patient with acid-labile subunit deficiency. Horm. Res. 67, 243-249

63. Domene, H. M., Scaglia, P. A., Lteif, A., Mahmud, F. H., Kirmani, S., Frystyk, J., Bedecarras, P., Gutierrez, M., and Jasper, H. G. (2007) Phenotypic effects of null and haploinsufficiency of acid-labile subunit in a family with two novel IGFALS gene mutations. J. Clin. Endocrinol. Metab. 92, 4444-4450

64. Hwa, V., Haeusler, G., Pratt, K. L., Little, B. M., Frisch, H., Koller, D., and Rosenfeld, R. G. (2006) Total absence of functional acid labile subunit, resulting in severe insulin-like growth factor deficiency and moderate growth failure. J. Clin. Endocrinol. Metab. 91, 1826-1831

Received for publication August 19, 2008 Accepted for publication October 2, 2008. 